\title{
Metabolic Stability of Glutaraldehyde Cross-Linked Peptide DNA Condensates
}

\author{
Roger C. Adami ${ }^{\dagger}$ and KeVIN G. Rice ${ }^{*,+, \neq}$ \\ Contribution from Divisions of Pharmaceutics and Medicinal Chemistry, College of Pharmacy, University of Michigan, \\ Ann Arbor, Michigan 48109-1065.
}

Received February 8, 1999. Accepted for publication May 25, 1999.

\begin{abstract}
The stability of peptide DNA condensates was examined after introducing glutaraldehyde to cross-link surface amine groups. A 20 amino acid peptide $\left(\mathrm{CWK}_{18}\right)$ was used to condense DNA into small $(70 \mathrm{~nm})$ condensates. The reaction between glutaraldehyde and peptide DNA condensates was indirectly monitored using a fluorescencebased assay to establish reaction completion in $4-5 \mathrm{~h}$ when using glutaraldehyde-to-peptide ratios of 1 to 4 mol equiv. Higher levels of glutaraldehyde cross-linking led to significant increases in particle size. The improved stability imparted by glutaraldehyde cross-linking was demonstrated by the increased resistance of DNA condensates to shear stress induced fragmentation. The cross-linked condensates were also significantly more resistant to in vitro metabolism by serum endonucleases. A decrease in the magnitude of transient gene expression was determined for cross-linked DNA condensates which also resulted in a 10-day steady-state expression when cross-linking with 4 mol equiv of glutaraldehyde. The results suggest that crosslinking DNA condensates may provide a means to alter the time course of transient gene expression by inhibiting DNA metabolism.
\end{abstract}

\section{Introduction}

To achieve optimal and prolonged gene expression, carrier molecules are used to protect plasmid DNA from metabolism while en route, and once inside the target cell.

* To whom correspondence should be addressed. Tel: 734-763-1032, fax: 734-763-2022, email: krice@umich.edu.

+ Division of Pharmaceutics.

₹ Division of Medicinal Chemistry.
Strategies to enhance nonviral DNA delivery have focused on the use of cationic carriers such as lipids, peptides, and polymers that bind DNA through ionic interaction. ${ }^{1-5}$ In each case, ion pairing leads to varying degrees of DNA condensation, resulting in cationic particles that internalize into cells and mediate transient gene expression. ${ }^{6}$

To be effective in delivering DNA, carrier molecules must have low toxicity, exhibit low levels of antigenicity or complement activation, and protect DNA from degradation. ${ }^{7}$ Simultaneously addressing each of these has been one of the major impediments to developing highly effective in vivo gene delivery formulations. , $^{1,8}$

The stability of DNA condensates in serum is dependent on the nature and affinity of a carrier molecule for binding DNA, the ionic strength, the concentration of endonuclease, and the presence of molecules that compete for carrier binding. Dissociation of the carrier molecule in serum exposes DNA to metabolizing endonuclease leading to premature degradation. ${ }^{9}$

Only a few studies have addressed the issue of DNA metabolism despite its obvious relationship to the level and duration of gene expression. ${ }^{9-13}$ Early studies by Wu and co-workers concluded that high molecular weight (HMW) polylysines could protect DNA from rapid metabolism in vitro for up to $1.5 \mathrm{~h} .{ }^{13}$ Subsequent studies by our group determined that a 20 amino acid peptide $\left(\mathrm{CWK}_{18}\right)$ was sufficient to stabilize DNA condensates from in vitro metabolism. ${ }^{14}$ Despite the ability of $\mathrm{HMW}$ polylysines to retard metabolism, the associated toxicity of these polymers has prompted the search for LMW carriers for use in vivo. ${ }^{15}$

An alternative strategy to achieve high affinity using LMW carriers is to provide temporary stability through 

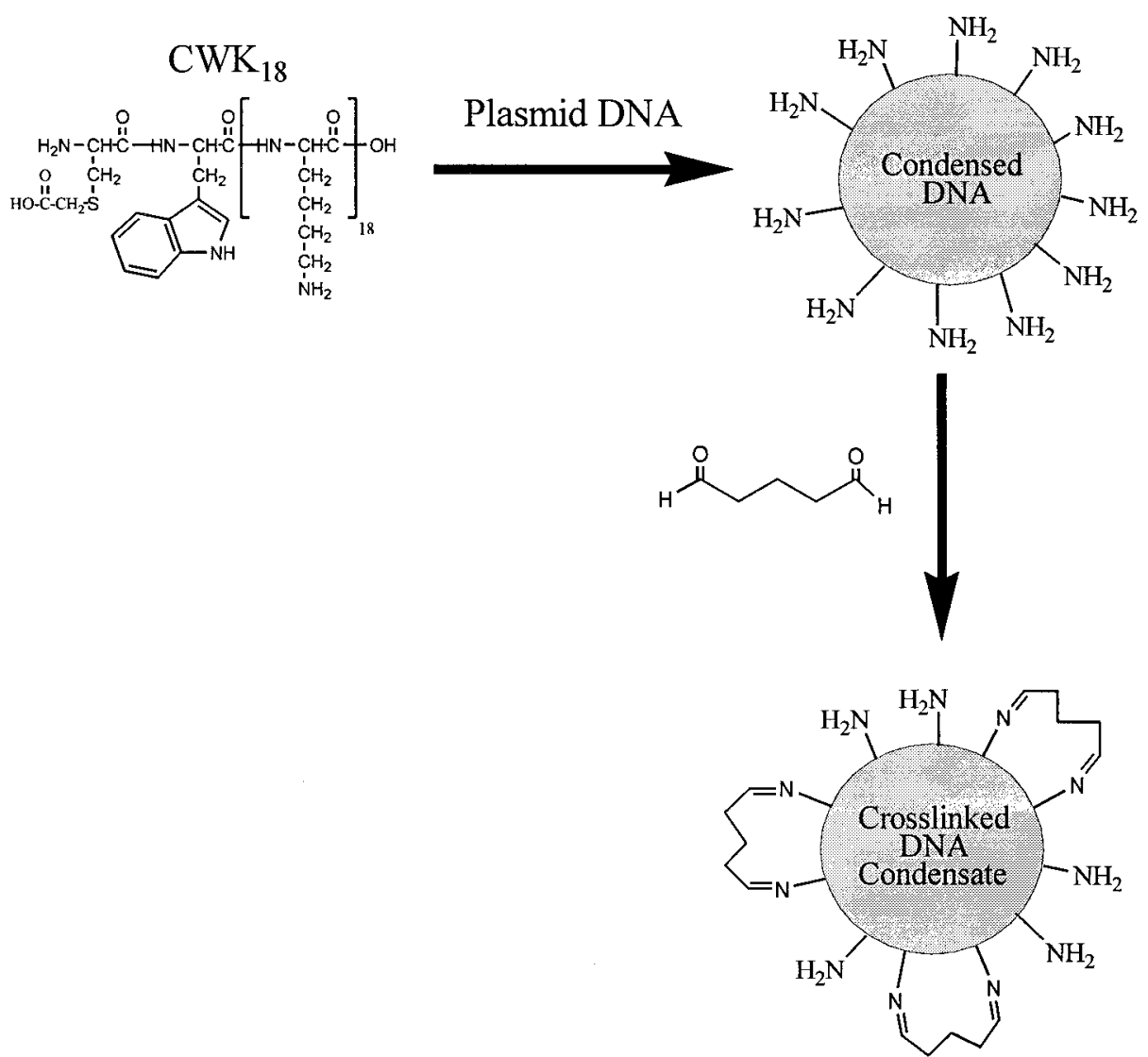

Figure 1-Glutaraldehyde cross-linking DNA condensates. CWK ${ }_{18}$ binds to plasmid DNA to spontaneously form condensed DNA possessing residual surface amines. Glutaraldehdye is reacted with condensed DNA resulting in the formation of two Schiff-bases between neighboring amine groups resulting in cross-linked DNA condensates. The degree of cross-linking is expressed as the mols of glutaraldehyde added relative to mols of $\mathrm{CWK}_{18}$.

molecular cross-linking of carriers on DNA condensates. The unpaired amines on the surface of peptide DNA condensates could potentially be cross-linked with a variety of agents.

Glutaraldehyde is a five-carbon dialdehyde which has long been used as a reagent to increase the tensile strength of transplanted pig heart valves and develop controlled release microspheres for drug delivery. ${ }^{16-18}$ The chemical cross-linking of albumin lysines with glutaraldehyde leads to particles which have controlled drug release properties. ${ }^{19,20}$ The degree of cross-linking directly affects the particle size, biodegradation, and release properties of drugs encapsulated in glutaraldehyde cross-linked microspheres. ${ }^{17,18,21}$

In the present study, we report the use of glutaral dehyde to cross-link DNA condensates in an attempt to improve their metabolic stability and alter the resulting transient gene expression profiles in vitro. The results indicate that cross-linking can be used to enhance the stability of LMW peptide DNA condensates and leads to steady-state transient gene expression. These attributes may allow the design of nonviral gene delivery carriers that mediate prolonged transient gene expression in vivo.

\section{Materials and Methods}

$\mathrm{CWK}_{18}$ (alkylated Cys-Trp-Lys 18 ) and dimeric CWK 18 were synthesized and characterized as described previously.22 Glutaraldehyde, SDS, ethidium bromide, proteinase K, DNase I (EC 3.1.21.1) from bovine pancreas, and polylysineg9, polylysine 476 , and polylysine 1007 were obtained from Sigma. pSEAP (plasmid secreted alkaline phosphatase with SV40 promoter and late polyadenylation sequence) and SEAP chemiluminescent detection kit were obtained from Clontech. pSEAP was grown in Escherichia coli and purified using a Qiagen miniprep column (Valencia, CA). TPCKtreated trypsin was obtained from Worthington Biochemicals (Freehold, NJ ). Bradford protein assay was obtained from BioRad (Hercules, CA). MEM, fetal calf serum and electrophoresis grade agarose were obtained from Gibco BRL (Gaithersburg, MD). SYBR-Gold was obtained from Molecular Probes (Eugene, OR).

Preparation and Characterization of Cross-Linked DNA Condensates- $\mathrm{CWK}_{18}$ DNA condensates were formed by adding $10 \mu \mathrm{g}(100 \mu \mathrm{L})$ of pSEAP $(4.7 \mathrm{kBp})$ to $3 \mathrm{nmol}$ of $\mathrm{CWK}_{18}$ in $100 \mu \mathrm{L}$ of $5 \mathrm{mM}$ HEPES, pH 7.4, while vortexing to prepare DNA condensates possessing a calculated charge ratio (amine:phosphate) of 2:1. HMW polylysines99-1007 were prepared at $10 \mathrm{mg} /$ $\mathrm{mL}$ in HEPES and used to form DNA condensates at a 2:1 amine: phosphate ratio for each.

After $30 \mathrm{~min}, \mathrm{CWK}_{18}$ DNA condensates were reacted with either $3,6,9$, or $12 \mathrm{nmol}$ of glutaraldehyde $(1 \mathrm{nmol} / u \mathrm{~L})$ for $12 \mathrm{~h}$ at $4{ }^{\circ} \mathrm{C}$ resulting in $1,2,3$, or $4 \mathrm{~mol}$ equiv (mol of glutaraldehyde per mol of $\mathrm{CWK}_{18}$ ) of cross-linking. The reaction of glutaraldehyde with DNA condensates was studied using a fluorophore exclusion assay. Following the addition of glutaraldehyde, $10 \mu \mathrm{L}$ aliquots were removed at time intervals ranging from 0 to $5 \mathrm{~h}$ and immediately combined with $490 \mu \mathrm{L}$ of $0.35 \mathrm{M}$ sodium chloride. Prior to measuring fluorescence, $10 \mu \mathrm{L}$ of SYBR-Gold (diluted 1:200 in DMSO) was added, and the fluorescence intensity (Ex: $495 \mathrm{~nm}$, E m: $537 \mathrm{~nm}$ ) was measured on a Perkin-EImer LS-50B fluorimeter.

The particle size of cross-linked DNA condensates was measured using $350 \mu \mathrm{L}$ of $50 \mu \mathrm{g} / \mathrm{mL}$ DNA condensate in HEPES by quasielastic light scattering (QELS). $\zeta$ potential measurements were conducted at the same DNA concentration in HEPES using an average of 10 runs to determine the mean and standard deviation on a Brookhaven ZetaPlus.

Shear Stress Stability of DNA Condensates-Peptide DNA condensates $(200 \mu \mathrm{L})$ were combined with $0-90 \mu \mathrm{L}$ of $5 \mathrm{M}$ sodium chloride and normalized with HEPES to a final volume of $300 \mu \mathrm{L}$ to obtain a final concentration of $0,0.1,0.3,0.5,0.7,0.9,1.2$, or $1.5 \mathrm{M}$ sodium chloride. A $100 \mathrm{~W}$ Microson XL-2000 ultrasonic 


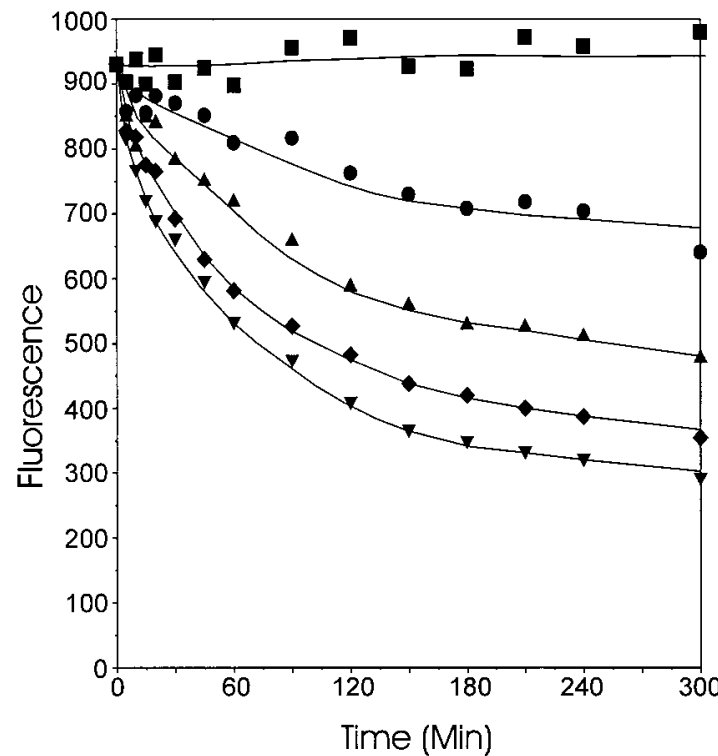

Figure 2-Kinetics of glutaraldehyde cross-linking $\mathrm{CWK}_{18}$ DNA condensates. The reaction between glutaraldehyde and condensed DNA was measured indirectly by a fluorescence assay described in Materials and Methods. An inverse relationship between the amount of glutaraldehyde added and fluorescence intensity indicated an increased reaction rate corresponding to increased glutaraldehyde cross-linking. The data represents un-cross-linked $(\boldsymbol{\square}), 1 \mathrm{~mol}$ equiv $(\mathbf{\bullet}), 2 \mathrm{~mol}$ equiv $(\mathbf{\Delta}), 3 \mathrm{~mol}$ equiv $(\bullet)$, and $4 \mathrm{~mol}$ equiv $(\boldsymbol{\nabla})$ cross-linked DNA condensates.

probe homogenizer (Kontes, Vineland, NJ) set at a vibrational amplitude of 5 was used throughout the study. The probe tip was placed $3 / 4$ depth into a $1.5 \mathrm{~mL}$ microfuge tube containing $300 \mu \mathrm{L}$ of sample and then sonicated for $30 \mathrm{~s}$. DNA samples ( $15 \mu \mathrm{L}$ ) were brought to $1 \mathrm{M}$ sodium chloride by adding $4.6 \mu \mathrm{L}$ of $5 \mathrm{M}$ sodium chloride and then digested with trypsin ( $3 \mu \mathrm{L}$ containing $7 \mathrm{U}$ ) for $12 \mathrm{~h}$ at $37^{\circ} \mathrm{C}$. The samples were combined with $3 \mu \mathrm{L}$ of loading buffer, and $18 \mu \mathrm{L}$ was applied to a $1 \%$ agarose gel $(50 \mathrm{~mL})$ containing $0.5 \mu \mathrm{g} / \mathrm{mL}$ ethidium bromide. The gel was electrophore sed in TAE buffer at $70 \mathrm{~V}$ for $80 \mathrm{~min}$ followed by $12 \mathrm{~h}$ destaining in deionized water. Transilluminated gels were photographed on polaroid 667 film

Serum Stability of DNA Condensates-DNA condensates (100 $\mu \mathrm{L}$ ) were combined with $100 \mu \mathrm{L}$ of DNase I augmented mouse serum $(0.12 \mathrm{U}$ of DNase I per $100 \mu \mathrm{L}$ serum) and $3 \mu \mathrm{L}$ of $5 \mathrm{M}$ sodium chloride to bring the final salt concentration to $150 \mathrm{mM}$. Samples were incubated at $37^{\circ} \mathrm{C}$ for $3 \mathrm{~h}$ while withdrawing 20 $\mu \mathrm{L}$ aliquots that were rapidly frozen at time points ranging from 0 to $180 \mathrm{~min}$. Serum samples were processed by adding $3 \mu \mathrm{L}(0.31$ $\mathrm{U}$ ) of proteinase $\mathrm{K}$ and then incubated at $37^{\circ} \mathrm{C}$ for $30 \mathrm{~min}$ to remove endonuclease activity. Sodium chloride was then added $(4.6 \mu \mathrm{L}$ of $5 \mathrm{M}$ ) along with trypsin ( $3 \mu \mathrm{L}$ containing $7 \mathrm{U}$ ) and allowed to digest for $12 \mathrm{~h}$ at $37^{\circ} \mathrm{C}$ to remove the cross-linked peptide. Samples were applied to a $1 \%$ agarose gel containing $0.05 \%$ SDS and electrophoresed as described above.

Transient Gene Expression-HepG2 cells $\left(3 \times 10^{5}\right)$ were plated on $6 \times 35 \mathrm{~mm}$ wells and grown for $48 \mathrm{~h}$ to $40 \%$ confluence in MEM supplemented with $10 \%$ fetal calf serum (FCS). Crosslinked DNA condensates (10 $\mu \mathrm{g}$ of DNA in $200 \mu \mathrm{L}$ ) were transfected in triplicate by dropwise addition to cells in $10 \%$ FCS either with or without $80 \mu \mathrm{M}$ chloroquine followed by $5 \mathrm{~h}$ incubation, after which the media was replaced with $2 \mathrm{~mL}$ of MEM containing $10 \%$ fetal calf serum and allowed to incubate for an additional $19 \mathrm{~h}$ Wells were sampled for 10-days at $24 \mathrm{~h}$ intervals by removing and freezing $\left(-20^{\circ} \mathrm{C}\right)$ the media and replacing it with $2 \mathrm{~mL}$ of fresh $10 \%$ FCS MEM. The amount of heat-stable SEAP in each well was determined using a chemiluminescent kit. Media (50 $\mu \mathrm{L})$ was combined with $50 \mu \mathrm{L}$ of dilution buffer followed by incubation at $65{ }^{\circ} \mathrm{C}$ for $30 \mathrm{~min}$ to denature endogenous alkaline phosphatase. Assay buffer $(100 \mu \mathrm{L})$ was added and incubated for 10 min at 25 ${ }^{\circ} \mathrm{C}$ followed by the addition of CSPD [(disodium 3-(4-methoxyspiro\{1,2-dioxetane-3,2'-(5'-chloro) tricyclo [3.3.1.1 $\left.{ }^{3,7}\right]$ decan\}-4-yl) phenyl phosphate)] substrate in chemiluminescent enhancer. After 30 min, the luminescence was measured with a 10 s integration on a
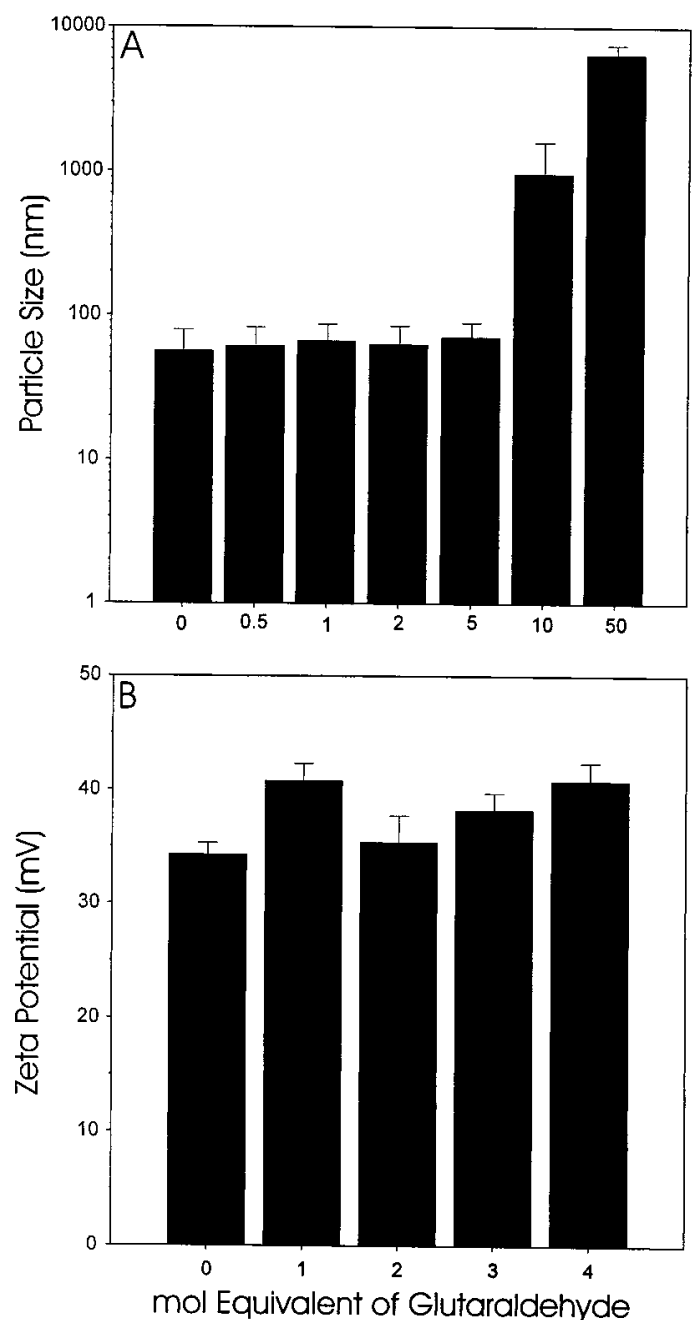

Figure 3-Particle size and $\xi$ potential analysis of cross-linked DNA condensates. CWK $_{18}$ DNA condensates cross-linked with $0-5 \mathrm{~mol}$ equiv of glutaraldehyde exhibited particle sizes between 55 and $70 \mathrm{~nm}$ as shown in panel A. At concentrations of 10 and 50 mol equiv of glutaraldehyde the particle size increased by 1 and 2 orders of magnitude (panel A). Condensates prepared at $0-4$ mol equiv of glutaraldehyde had a $\xi$ potential between +34 $41 \mathrm{mV}$ (panel B).

Berthold Lumat LB 9501 luminometer. Light units were converted to $\mu \mathrm{g} / \mathrm{mL}$ of SEAP using a standard curve constructed by adding known quantities of SEAP to cell homogenate. Residual endogenous alkaline phosphatase background was determined from a 10-day null control and subtracted from each data set.

\section{Results}

The metabolic stability and transient gene expression was investigated in relationship to the degree of crosslinking applied to peptide DNA condensates. Peptide DNA condensates are colloids that possess primary amines on their surface that can be cross-linked with homobifunctional agents such as glutaraldehyde (Figure 1). The resulting interpeptide cross-links should stabilize condensed DNA from peptide dissociation and from metabolism since it has been previously established that condensed DNA resists endonuclease attack.13,14

To establish that glutaraldehyde reacts with DNA condensates to form interpeptide cross-links the time course of the reaction was monitored indirectly using a fluorescent intercalator dye. SYBR-Gold was selected since its intercalation into DNA is not significantly inhibited in sodium chloride up to $1 \mathrm{M}$. In the absence of sodium 


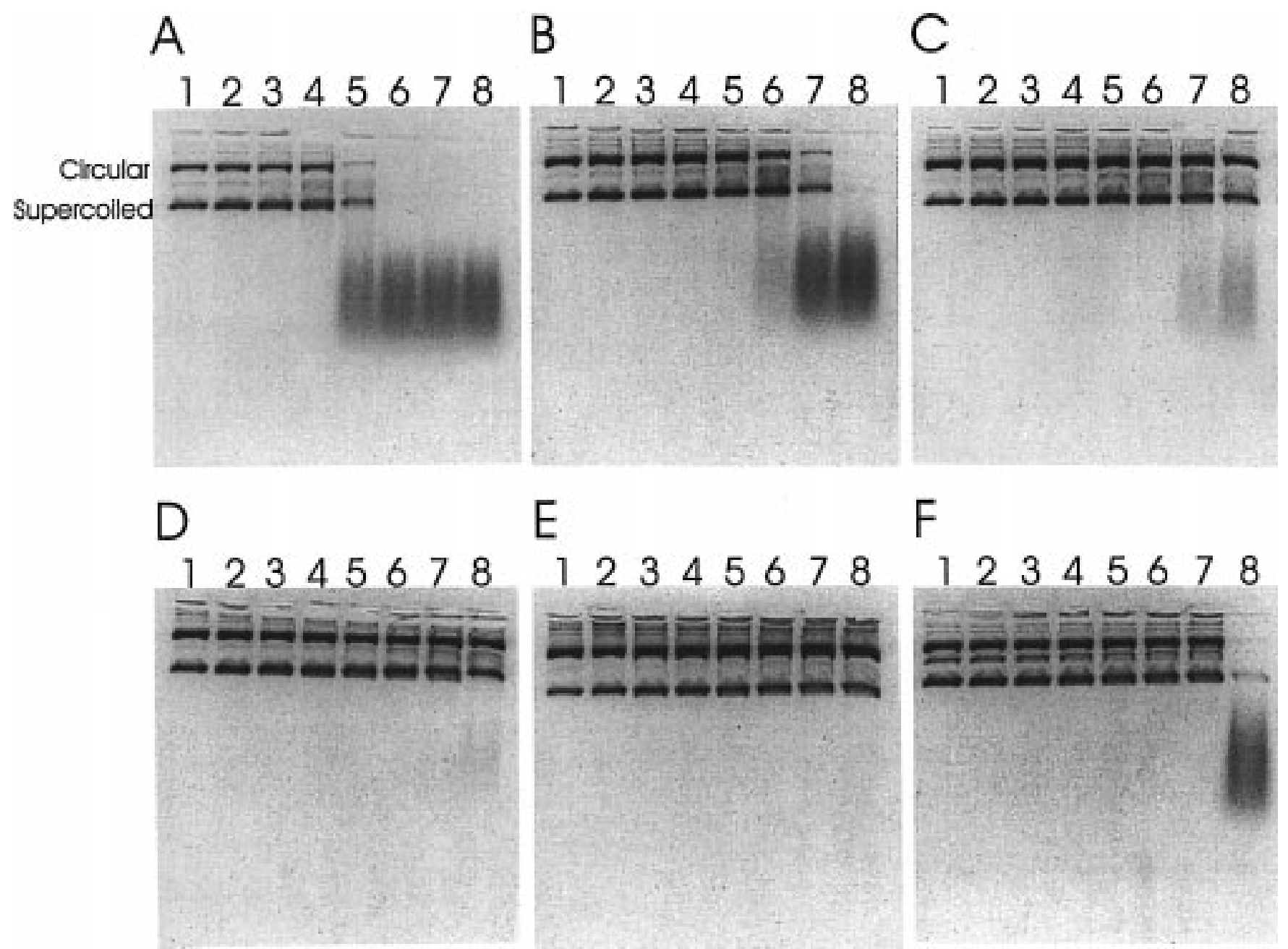

Figure 4-Shear stress stability of cross-linked DNA condensates. The stability of cross-linked DNA condensates was measured by $30 \mathrm{~s} 100 \mathrm{~W}$ sonication in the presence of increasing sodium chloride concentration as described in Methods and Methods. The electrophoretic analysis of CWK ${ }_{18}$ DNA condensates prepared with $0(\mathrm{~A}), 1(\mathrm{~B}), 2(\mathrm{C}), 3(\mathrm{D})$ and $4(\mathrm{E})$ mol equiv of glutaraldehyde were compared to polylysine ${ }_{1007}$ DNA condensates $(\mathrm{F})$. Lanes 1 through 8 contain $0,0.1$, $0.3,0.5,0.7,0.9,1.2$, and $1.5 \mathrm{M}$ sodium chloride. The dissociation of $\mathrm{CWK}_{18}$ from DNA occurs at $0.7 \mathrm{M}$ sodium chloride (panel $\mathrm{A}$, lane 5 ) as determined by the formation of fragments during sonication. Alternatively, 1 mol equiv of glutaraldehyde extended the DNA stability to $0.9 \mathrm{M}$ sodium chloride (panel B, lane 6), 2 mol equiv of glutaraldehyde increased the stability to $1.2 \mathrm{M}$ sodium chloride (panel $\mathrm{C}$, lane 7), and 3 and 4 mol equiv of glutaraldehyde resulted in DNA condensates that were stable in $1.5 \mathrm{M}$ sodium chloride (panels $\mathrm{D}$ and $\mathrm{E}$ ). In contrast, polylysine ${ }_{1007}$ DNA condensates dissociate in $1.5 \mathrm{M}$ sodium chloride (panel $\mathrm{F}$, lane 8). Each result was replicated twice.

chloride, the reaction of SYBR-Gold with $\mathrm{CWK}_{18}$ DNA condensates produces minimal fluorescence whereas the partial dissociation of condensates that occurred in 0.35 $\mathrm{M}$ sodium chloride produced a maximal fluorescence following intercalation (Figure 2). After the addition of glutaraldehyde, the formation of interpeptide cross-links stabilized $\mathrm{CWK}_{18}$ DNA condensates from dissociating in $0.35 \mathrm{M}$ sodium chloride, leading to a decrease in the fluorescence intensity as the reaction proceeded over $5 \mathrm{~h}$ (Figure 2). Analysis of the reaction profile while varying the stoichiometry of glutaraldehyde from 1 to $4 \mathrm{~mol}$ equiv establ ished a progressive decrease in fluorescence intensity that approached reaction completion in $5 \mathrm{~h}$, suggesting that increasing the glutaraldehyde concentration leads to the formation of additional cross-links and further stabilization of DNA condensates (Figure 2).

Since glutaraldehyde could potentially also produce interparticle cross-links leading to larger DNA condensates, the relationship between the degree of cross-linking and the particle size was investigated by QELS analysis. DNA condensates prepared with 1 to 5 mol equiv of glutaraldehyde maintained a particle size of $55-70 \mathrm{~nm}$, whereas stoichiometries of $10 \mathrm{~mol}$ equiv or higher caused a significant increase in size suggesting the formation of interpar- ticle cross-links (Figure 3A). At 4 mol equiv of glutaraldehyde or lower, the $\xi$ potential of DNA condensates remained between $+34-41 \mathrm{mV}$, establishing minimal change in the overall charge of DNA condensates (Figure 3B).

The shear stress stability of glutaraldehyde cross-linked DNA condensates was evaluated by gel electrophoresis. $\mathrm{CWK}_{18}$ DNA condensates resist fragmentation when subjected to $30 \mathrm{~s}$ sonication until the sodium chloride concentration reached $0.7 \mathrm{M}$ or higher, causing dissociation of peptide resulting in DNA fragmentation during sonication (F igure 4A). By comparison, DN A condensates cross-linked with 1 mol equiv of glutaraldehyde resist fragmentation in $0.9 \mathrm{M}$ sodium chloride (Figure 4B). Reaction with $2 \mathrm{~mol}$ equiv of glutaral dehyde led to further stabilization resulting in condensates that resist fragmentation in $1.2 \mathrm{M}$ sodium chloride (Figure 4C). Increasing the cross-linking to 3 and $4 \mathrm{~mol}$ equiv of glutaraldehyde resulted in DNA condensates that were stable up to $1.5 \mathrm{M}$ sodium chloride (Figure 4D and 4E). Alternatively, polylysine 1007 DNA condensates were found to be less stable, undergoing fragmentation during sonication in $1.5 \mathrm{M}$ sodium chloride (Figure 4F). These results suggest that the interpeptide cross-links formed with 3 and 4 mol equiv of glutaral dehyde extend the stability of $\mathrm{CWK}_{18}$ DNA condensates beyond 

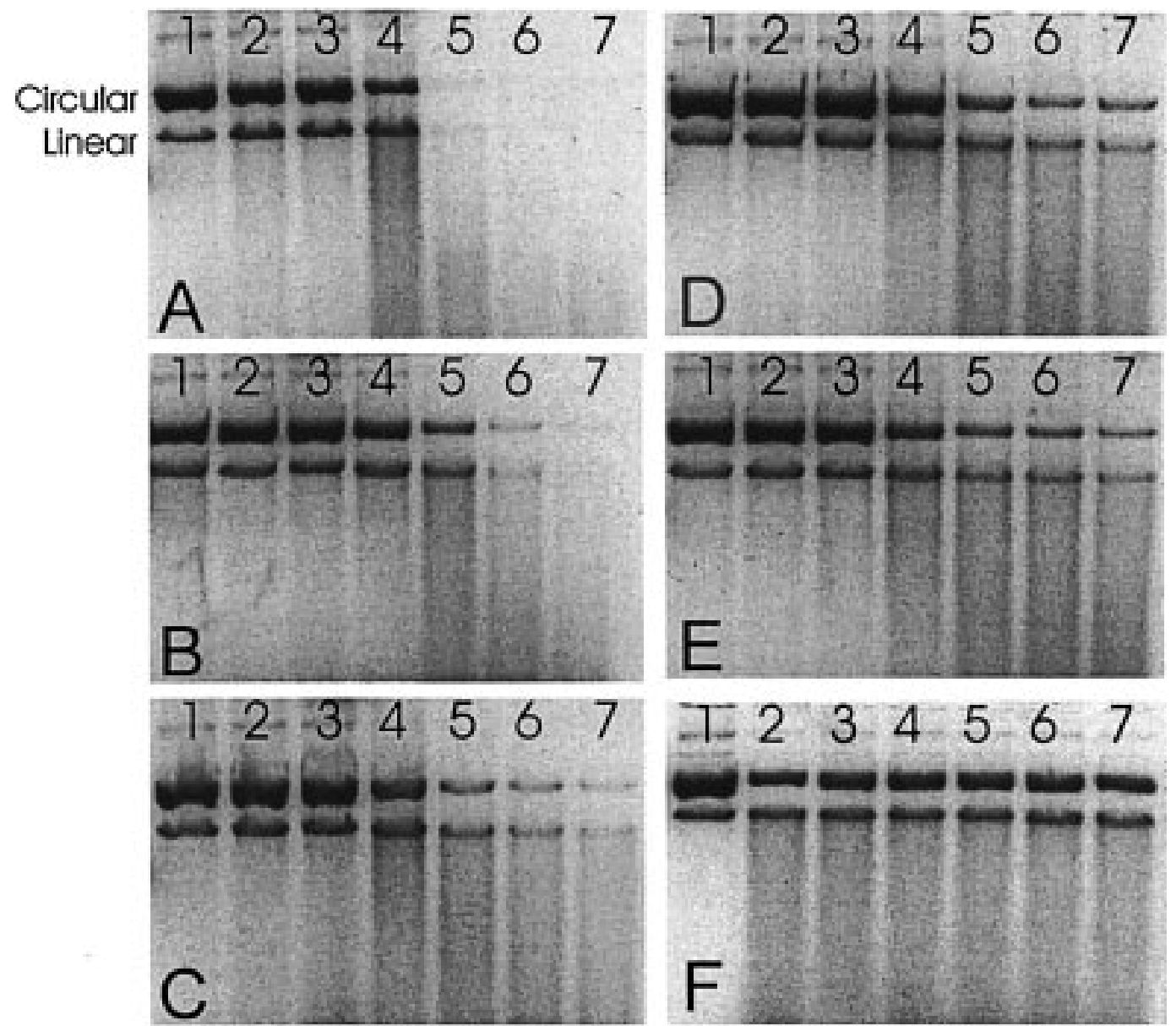

Figure 5-Serum stability of cross-linked condensates. The serum stability of DNA condensates cross-linked with 0 (A), 1 (B), 2 (C), 3 (D) and 4 (E) mol equiv of glutaraldehyde are compared to polylysine 1007 DNA condensates $(F)$ using gel electrophoresis. Lanes 1 through 7 correspond to $0,15,30,60,90,120$, and 180 min digestion period. DNA stability was determined by observing a progressive decrease in the intensity of the circular and linear bands during the digestion, ultimately leading to the disappearance of the bands. Metabolism was evident from a decrease in band intensity leading to the complete disappearance of bands after $60 \mathrm{~min}$ for un-cross-linked DNA condensates (panel A, lane 4). DNA condensates prepared with $1 \mathrm{~mol}$ equiv of glutaraldehyde were delayed in metabolism until $90 \mathrm{~min}$ (panel B, lane 5). DNA condensates prepared with 2, 3, and 4 mol equiv of glutaraldehyde were significantly more protected from metabolism during the 180 min digestion, exhibiting only a decrease in the band intensity for circular and linear DNA (panels C-D, lanes 5-7). Polylysine ${ }_{1007}$ was better than cross-linked condensates at protecting DNA throughout the 180 min digestion (panel F). Each results was replicated twice.

that achievable with a HMW polylysine. Control experiments established that plasmid DNA did not change its gel electrophoretic banding pattern when reacted with glutaraldehyde, suggesting that the exocylic amines on plasmid DNA bases are inexcessible to Schiff-base formation.

To be effective in gene delivery, cross-linked DNA condensates should al so resist digestion with serum endonucleases. The metabolic stability of DNA was examined by gel electrophoretic analysis of DNA condensates incubated in mouse serum. Since un-cross-linked CWK ${ }_{18}$ DNA condensates proved to be resistant to endogenous serum endonuclease during a $24 \mathrm{~h}$ incubation, exogenous DNase I was added to accelerate the metabolism into a $3 \mathrm{~h}$ time period. Incubation of $\mathrm{CWK}_{18}$ DNA condensates in $50 \%$ serum containing 0.12 units of DNase I resulted in metabol ism into ol igonucleotides after $60 \mathrm{~min}$ (Figure 5A, lane 5). A trypsin contaminant produced a single strand nick in the DNA, such that even at time zero only circular and linear forms of DNA were recovered. Cross-linking CWK $_{18}$ DNA condensates with 1-4 mol equiv of glutaraldehyde produced a progressive increase in metabolic stability with even 1 mol equiv of glutaral dehyde extending the stability of DNA condensates from 60 to $90 \mathrm{~min}$ (Figure 5B). The addition of 2 to $4 \mathrm{~mol}$ equiv extended the stability even further as evidenced by an increase in band intensity at 90 to $180 \mathrm{~min}$ (Figure 5C-E) ). By comparison, polylysine 1007
DNA condensates demonstrate improved serum stability to that of glutaraldehyde cross-linking at $4 \mathrm{~mol}$ equiv (Figure 5F).

The cytotoxicity of both free glutaral dehyde and crosslinked DNA condensates were examined in cell culture. The total protein of cell homogenates harvested $24 \mathrm{~h}$ after transfecting cells in the presence of free glutaral dehyde or cross-linked DNA condensates were indistinguishable from control, indicating no toxicity when using 1-4 mol equiv of glutaraldehyde corresponding to $1.5-6 \mu \mathrm{M}$.

The ability of cross-linked DNA condensates to release DNA and mediate gene transfer was examined by measuring the alkaline phosphatase secreted from HepG2 cells over a 10-day period. When using chloroquine to augment endosomal escape and increase gene expression, un-crosslinked peptide DNA condensates produced a transient gene expression profile that peaked around day 3-4 and then decreased to near background by day 10 (Figure 6A), with total transgene expression reaching $1.5 \mu \mathrm{g}$ (Figure 6B). The moderate increase in stability afforded by 1 mol equiv of glutaraldehyde resulted in an expression profile and cumulative SEAP production identical to that afforded by un-cross-linked condensates. Alternatively, cross-linking with 2 mol equiv of glutaraldehyde resulted in a peak expression level that was nearly 2-fold greater than uncross-linked DNA condensates (Figure 6A). These results are in contrast with those using 3 mol equiv of glutaral- 

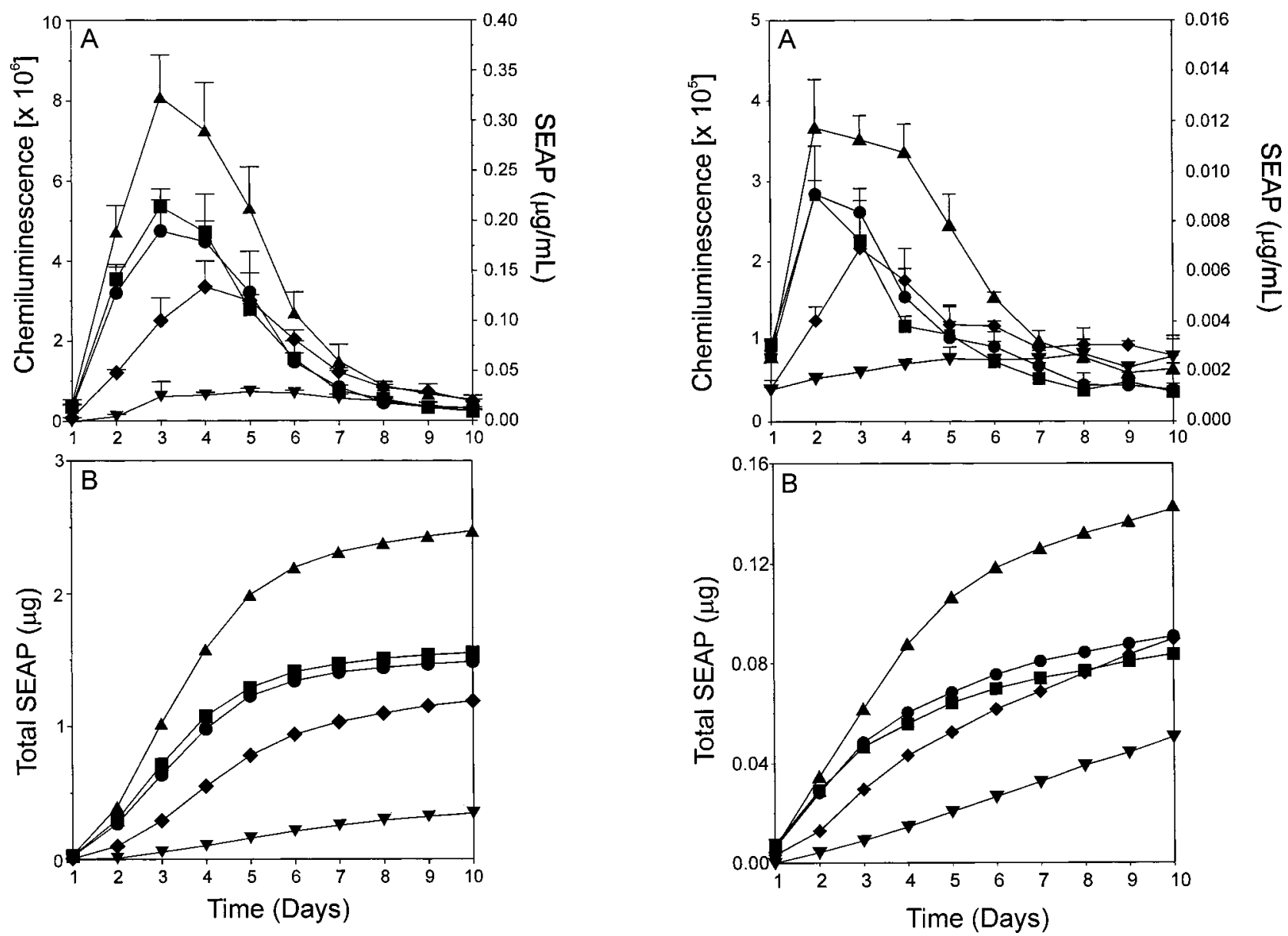

Figure 6-Transient gene expression profiles for cross-linked DNA condensates in the presence of chloroquine. The 10-day HepG2 SEAP expression profiles for cross-linked DNA condensates when including chloroquine in the transfection are shown in panel $A$. The data represents the mean and standard deviation when using un-cross-linked $(\boldsymbol{\square}), 1 \mathrm{~mol}$ equiv $(\mathbf{\bullet}), 2 \mathrm{~mol}$ equiv $(\boldsymbol{\Delta})$, $3 \mathrm{~mol}$ equiv ( ), and $4 \mathrm{~mol}$ equiv ( $\boldsymbol{\nabla})$ cross-linked DNA condensates. The cumulative SEAP production for each DNA condensate is plotted in panel $\mathrm{B}$. The slope of the day 7-10 cumulative expression was $28.3 \mathrm{ng} / \mathrm{mL} \mathbf{\square}, 26.8$ $\mathrm{ng} / \mathrm{mL} \bullet, 52.8 \mathrm{ng} / \mathrm{mL} \boldsymbol{\Delta}$, and $52.9 \mathrm{ng} / \mathrm{mL} \bullet$ with $r^{2} \geq 0.965$ for each.

dehyde which led to a $30 \%$ decrease in the maximal expression level. Likewise, the maximal expression determined for 4 mol equiv cross-linked DNA condensate was reduced by approximately $80 \%$ compared to $\mathrm{CWK}_{18}$ DNA condensates.

Comparison of the cumulative SEAP production for each condensate established a range of 0.3 to $2.2 \mu \mathrm{g}$ over the 10-day period (Figure 6B). Un-cross-linked condensates and cross-linked condensates possessing 1-3 mol equiv of glutaraldehyde approached a plateau in total SEAP production at day 6 . The day 7-10 SEAP production for 2 and 3 mol equiv cross-linked DNA continued at a rate that was 2-fold greater than that of un-cross-linked or 1 mol equiv cross-linked DNA condensates as determined by linear regression of days 7-10. However, the SEAP production mediated by $\mathrm{CWK}_{18}$ DNA condensates cross-linked with 4 mol equiv of glutaraldehyde was constant throughout day $1-10$ resulting in a linear regression line with a slope of $42 \mathrm{ng} /$ day and $\mathrm{r}^{2}=0.986$ (Figure 6B).

When chloroquine was omitted from the assay, the transient gene expression mediated by each peptide DNA condensate was reduced by over 1 order of magnitude (Figure 7A). As was also found for transfection in the presence of chloroquine, the cumulative gene production for 2 and 3 mol equiv cross-linked DNA condensates produced day 7-10 slopes that were 2-fold greater than

Figure 7-Transient gene expression profiles for cross-linked DNA condensates in the absence of chloroquine. The 10-day HepG2 SEAP expression profile mediated for cross-linked DNA condensates when omitting chloroquine from the transfection are shown in panel $A$. The data represents the mean and standard deviations when using un-cross-linked $(\boldsymbol{\square}), 1 \mathrm{~mol}$ equiv $(\mathbf{0}), 2 \mathrm{~mol}$ equiv $(\mathbf{\Delta}), 3 \mathrm{~mol}$ equiv $(\boldsymbol{\bullet})$, and $4 \mathrm{~mol}$ equiv $(\boldsymbol{\nabla})$ cross-linked DNA condensates. The cumulative SEAP production for each DNA condensate is plotted in panel B. The slope of the day 7-10 cumulative expression was 3.3 $\mathrm{ng} / \mathrm{mL} \mathbf{\square}, 3.4 \mathrm{ng} / \mathrm{mL} \bullet, 5.2 \mathrm{ng} / \mathrm{mL} \mathbf{\Delta}$, and $7.1 \mathrm{ng} / \mathrm{mL} \bullet$ with $r^{2} \geq 0.996$ for each.

un-cross-linked or 1 mol equiv cross-linked DNA condensates (Figure 7B). In addition, the cumulative expression for day $1-10$ was linear $\left(r^{2}=0.999\right)$ with a slope of 5.7 ng/day when using $4 \mathrm{~mol}$ equiv of gl utaral dehyde to crosslink DNA condensates, indicating a steady-state expression of SEAP (Figure 7B).

A possible consequence of glutaraldehyde cross-linking could be the formation of long polylysine chains. To confirm that the expression profiles are not the result of linear polymerization of $\mathrm{CWK}_{18}$ the transient gene expression profile was studied using DNA condensates prepared with a panel of $\mathrm{HMW}$ polylysines (Figure 8A). The expression of SEAP exhibited a peak intensity correlating directly with the increase in chain length of polylysine, with each peptide DNA condensate mediating a maximum in the gene expression at day 3-4 (Figure 8A). Dimeric CWK ${ }_{18}$ DNA condensates produced approximately $10 \%$ more gene product relative to $\mathrm{CWK}_{18}$ DNA condensates. Polylysine 99 resulted in nearly 1.5-fold greater gene expression, whereas the greatest levels of transient gene expression were achieved with polylysine 476 and 1007 DNA condensates which produced 2.1 and 3.2-fold greater gene expression than $\mathrm{CWK}_{18}$ DNA condensates (Figure 8B). Likewise, the cumulative SEAP expression for days 7-10 also demon- 

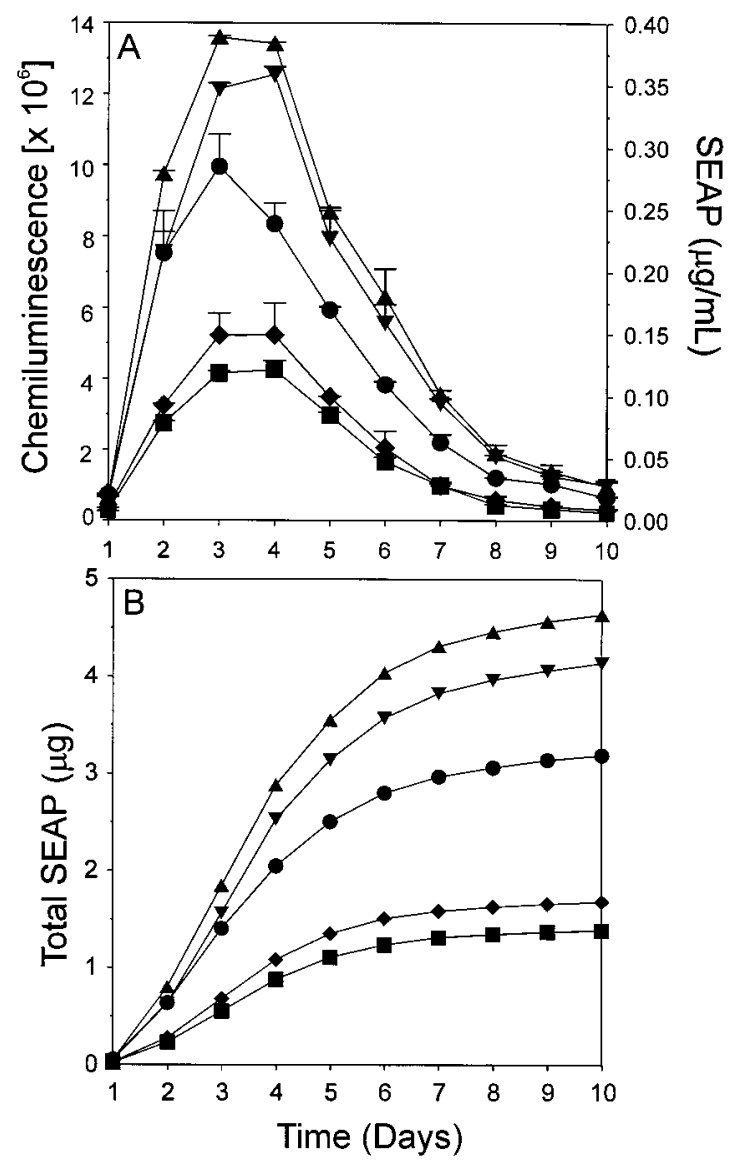

Figure 8-Transient gene expression profiles for HMW polylysine DNA condensates. The 10-day HepG2 SEAP expression profiles are compared for

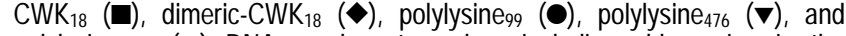
polylysine $_{1007}(\mathbf{\Lambda})$ DNA condensates when including chloroquine in the transfection are shown in panel A. The cumulative SEAP production for each DNA condensate is plotted in panel $\mathrm{B}$. The slope of the day 7-10 cumulative expression was $25.5 \mathrm{ng} / \mathrm{mL} \mathbf{\square}, 32.7 \mathrm{ng} / \mathrm{mL} \bullet, 74.7 \mathrm{ng} / \mathrm{mL} \bullet, 103.7 \mathrm{ng} / \mathrm{mL}$ $\boldsymbol{\nabla}$ and $109.3 \mathrm{ng} / \mathrm{mL} \boldsymbol{\Delta}$ with $r^{2} \geq 0.978$ for each.

strated a 3-fold increase in slope when comparing $\mathrm{CWK}_{18}$ DNA and polylysine 1007 DNA condensates.

\section{Discussion}

The stability of a DNA formulation is fundamental to its successful application in vivo since metabolism results in the generation of fragmented DNA which no longer mediates gene expression. ${ }^{14}$ Even though peptide DNA condensates are more resistant to metabolism than naked plasmid DNA ${ }^{11}$ or cationic lipid DNA condensates, 10,23 the in vitro stability determined by incubating condensates in serum may not be predictive of the in vivo stability in which the carrier molecules dissociate and are removed during circulation. This is exemplified by earlier studies by $\mathrm{Wu}$ and co-workers which showed the prolonged stability of DNA condensates in vitro ${ }^{13}$ but a more limited stability in vivo. ${ }^{24}$

Even though a short polylysine peptide of 20 amino acids is sufficient to condense DNA into small condensates of approximately $70 \mathrm{~nm}$ diameter, HMW polylysines $38-1007$ offer the advantage of binding to DNA with higher affinity, resulting in a greater protection of DNA to metabolism. However, there are also significant drawbacks in using HMW polylysine to create carriers for gene delivery. The polydispersity of HMW polylysine results in batch to batch variation. ${ }^{25}$ The derivatization of HMW polylysine with ligands or polyethlene glycol is achieved by random cou- pling reactions which cannot control the conjugation site along the polylysine chain creating further heterogeneity in the carrier molecule.26-28 Perhaps most significant, is the known cytotoxicity, complement activation, and inflammation mediated by HMW polylysine. ${ }^{29}$ Given these limitations we have focused our efforts on developing LMW DNA carriers that are homogeneous, condense DNA into small condensates, may be selectively derivatized, and are minimal in size to reduce toxicity.

To overcome the limited stability afforded by LMW DNA carriers, we propose to introduce interchain cross-links to preformed DNA condensates to further improve their stability. The advantage of this approach is the ability to vary the degree of cross-linking to create condensates that possess the required stability for different gene therapy applications. Also, a variety of cross-linking agents could potentially be used alone or in combination to create controlled release of the DNA upon hydrolysis and dissociation of the cross-linker and carrier. Control over these events is a prerequisite to achieving delayed or prolonged transgene expression.

The test of this hypothesis was conducted by attempting to cross-link the surface amine groups on $\mathrm{CWK}_{18}$ DNA condensates using glutaraldehyde. This cross-linker was chosen because of its prior use in developing cross-linked albumin microspheres for parenteral applications, ${ }^{20}$ its safety record when used in a variety of prosthesis, 30 and the Schiff-base that forms is theoretically reversible.16,31 The results indicate that $\mathrm{CWK}_{18}$ DNA condensates undergo cross-linking over a $4-5 \mathrm{~h}$ period when very low concentrations of glutaraldehyde ( $1-4 \mathrm{~mol}$ equiv relative to $\mathrm{CWK}_{18}$ ) are added. This amount of glutaraldehyde is far below the amounts needed to observe toxicity in cells grown in culture. Likewise, the maximum amount of glutaral dehyde used (4 mol equiv) can theoretically cross-link $20 \%$ of the amines present, assuming glutaraldehyde distributes equally throughout the DNA condensates. At this low level, the particle size is maintained, the $\zeta$ potential of the DNA condensates is unaffected, and trypsin can still be used to enzymatically remove $\mathrm{CWK}_{18}$ to quantitatively rel ease the DNA. However, despite numerous attempts, we could not demonstrate the spontaneous reversal of glutaraldehyde cross-linked DNA condensates on prolonged dialysis in the presence of protein.

One measure that establishes the relative stability of peptide DNA condensates is the ability of DNA to resist fragmentation during a $30 \mathrm{~s} 100 \mathrm{~W}$ sonication in a dissociating concentration of sodium chloride. Cross-linked DNA condensates were increasingly stable to sonicative fragmentation at cross-linking levels ranging from 1 to 4 mol equiv of glutaraldehyde and were even found to be more stable than HMW polylysine g9-1007 DNA condensates. This result suggests that interchain peptide cross-links, and not linear polymerization of $\mathrm{CWK}_{18}$, are responsible for the observed stabilization.

A similar correlation was observed from in vitro metabolism studies that indicated that 4 mol equiv cross-linked DNA condensates were significantly stabilized but still inferior to polylysine 1007 in their ability to protect DNA from accelerated metabolism. Interestingly, DNA condensates with and without cross-linking appeared to be directly metabolized into fragments without going through the linear form (Figure 5). This is in contrast to the catabolism of naked DNA which is converted completely into linear DNA prior to the formation of fragments. ${ }^{14} \mathrm{It}$ is al so evident that intracellular proteolysis must somehow be involved in the release of DNA from cross-linked condensates since it less likely that the spontaneous reversal of Schiff-base is the major route of DNA release prior to gene expression.

Clearly, the ability of cross-linked DNA condensates to 
mediate gene expression is an important measure of their ability to be useful in gene therapy applications. Since cross-linking could delay the release of DNA inside cells, it was important to study the transient gene expression as opposed to a single 24 or $48 \mathrm{~h}$ expression level. However, this was also technically challenging due to the doubling rate of cells in culture which slows as they reach confluence. At an optimal seeding density, cell cultures could be maintained for 10 days, and the gene expression occurring each day was determined using secreted alkaline phosphatase. The most significant effect of cross-linking DNA condensates, in addition to stabilization to metabolism, was an apparent flattening of the expression profile such that 4 mol equiv cross-linking of DNA condensates resulted in a low level of steady-state expression over the 10-day transfection which could not be extended in cell culture. Omitting chloroquine more closely models in vivo conditions and further confirmed that cross-linking could produce a steady-state rate of expression.

Analysis of the transient gene expression profile for HMW polylysine $38-1007$ DNA condensates indicated a correlation between the cummulative gene expression and the degree of polymerization. We interpret these results as partial validation of the hypothesis that increasing the DNA condensate stability will result in greater gene expression.

Futurestudies will examinethe influence of cross-linking to prolong the survival of DNA in vivo and to stabilized DNA condensates prepared with more than one LMW carrier to endow the delivery system with specific targeting. The methods developed and used in this study have established the principle of cross-linking DNA condensates using glutaraldehyde and should allow testing of other cross-linkers to stabilize peptide DNA condensates from metabolism leading to prolonged gene expression in vivo.

\section{References and Notes}

1. Duguid, J . G.; Li, C.; Shi, M.; Logan, M.J .; Alila, H.; Rolland, A.; Tomlinson, E.; Sparrow, J. T.; Smith, L. C. A Physicochemical Approach for Predicting the Effectiveness of Peptide-Based Gene Delivery Systems for Use in Plasmid-Based Gene Therapy. Biophysical J . 1998, 74, 2802-2814.

2. Niidome, T.; Ohmori, N.; I chinose, A.; Wada, A.; Mihara, H.; Hirayama, T.; Aoyagi, H. Binding of Cationic $\alpha$-Helical Peptides to Plasmid DNA and Their Gene Transfer Abilities into Cells. J . Biol. Chem. 1997, 272, 15307-15312.

3. Pouton, C. W.; Lucas, P.; Thomas, B. J .; Uduehi, A. N. Milroy, D. A.; Moss, S. H. Polycation-DNA complexes for gene delivery: a comparison of the biopharmaceutical properties of cationic polypeptides and cationic lipids. J . Controlled Release 1998, 53, 289-299.

4. Perales, J . C.; Grossmann, G. A.; Molas, M.; Liu, G.; Ferkol T.; Harpst, J.; Oda, H.; Hanson, R. W. Biochemical and functional characterization of DNA complexes capable of targeting genes to hepatocytes via the asialoglycoprotein receptor. J . Biol. Chem. 1997, 272, 7398-407.

5. Wagner, E.; Cotten, M.; Mechtler, K.; Kirlappos, H.; Birnstiel, M. L. DNA-binding transferrin conjugates as functional genedelivery agents: synthesis by linkage of polylysine or ethidium homodimer to the transferrin carbohydrate moiety. Bioconjugate Chem. 1991, 2, 226-31.

6. Kabanov, A. V.; Kabanov, V. A. DNA complexes with polycations for the delivery of genetic material into cells. Bioconjugate Chem. 1995, 6, 7-20.

7. Ledley, F. Pharmaceutical Approach to Somatic Gene Therapy. Pharm. Res. 1996, 13, 1595-1614.

8. Mahato, R. I.; Rolland, A.; Tomlinson, E. Cationic LipidBased Gene Delivery Systems: Pharmaceutical Perspectives. Pharm. Res. 1997, 14, 853-859.

9. Yang, J. P.; Huang, L. Overcoming the inhibitory effect of serum on lipofection by increasing the charge ratio of cationic liposome to DNA. Gene Ther. 1997, 4, 950-60.

10. Escriou, V.; Ciolina, C.; Lacroix, F.; Byk, G.; Scherman, D.; Wils, P. Cationic lipid-mediated gene transfer: effect of serum on cellular uptake and intracellular fate of lipopolyamine/DNA complexes. Biochimica et Biophys. Acta 1998, 1368, 276-288.

746 / Journal of Pharmaceutical Sciences Vol. 88, No. 8, August 1999
11. Katayose, S.; Kataoka, K. Remarkable increase in nuclease resistance of plasmid DNA through supramol ecular assembly with poly(ethylene glycol)-poly(L-lysine) block copolymer. J. Pharm. Sci. 1998, 87, 160-163.

12. Liu, F.; Liu, D. Serum independent liposome uptake by mouse liver. Biochim. Biophys. Acta 1996, 1278, 5-11.

13. Chiou, H. C.; Tangco, M. V.; Levine, S. M.; Robertson, D. Kormis, K.; Wu, C. H.; Wu, G. Y. Enhanced resistance to nuclease degradation of nucleic acids complexed to asialoglycoprotein-polylysine carriers. Nucleic Acids Res. 1994, 22, 5439-46.

14. Adami, R. C.; Collard, W. T.; Gupta, S. A.; Kwok, K. Y.; Bonadio, J.; Rice, K. G. Stability of Peptide-Condensed Plasmid DNA Formulations. J . Pharm. Sci. 1998, 87, 678683

15. Gottschalk, S.; Sparrow, J . T.; Hauer, J .; Mims, M. P.; Leland, F. E.; Woo, S. L. C.; Smith, L. C. A novel DNA-peptide complex for efficient gene transfer and expression in mammalian cells. Gene Ther. 1996, 3, 448-457.

16. Jayakrishnan, A.; J ameela, S. R. Glultaraldehyde as a Fixative in Bioprostheses and Drug Delivery Matrixes. Biomaterials 1996, 17, 471-484.

17. J ones, C.; Burton, M. A.; Gray, B. N. Albumin microspheres as vehicles for the sustained and controlled release of doxorubicin. J . Pharm. Pharmacol. 1989, 41, 813-816.

18. Gupta, P. K., and C. T. Hung. Albumin microspheres I: physicochemical characteristics. J. Microencaps. 1989, 6, 427-462.

19. Lin, W.; Coombes, A. G. A.; Garnett, M. C.; Davies, M. C.; Schact, E.; Davis, S. S.; Illum, L. Preparation of sterically stabilized human serum al bumin nanospheres using a novel dextranox-MPEG cross-linking agent. Pharm. Res. 1994, 11, 1588-1592.

20. Royer, G. P.; Lee, T. K. Entrapment of bioactive compounds within native albumin beads. J . Parent. Sci. Technol. 1983, 37, 34-37.

21. Leong, K. W.; Mao, H. Q.; Truong-Le, V. L.; Roy, K.; Walsh S. M.; August, J . T. DNA-polycation nanospheres as nonviral gene delivery vehicles. J . Control led Rel ease 1998, 53, 183193.

22. Wadhwa, M. S.; Collard, W. T.; Adami, R. C.; McKenzie, D. L.; Rice, K. G. Peptide-mediated gene delivery: influence of peptide structure on gene expression. Bioconjugate Chem. 1997, 8, 81-88.

23. Thierry, A. R.; Rabinovich, P.; Peng, B.; Mahan, L. C.; Bryant, J . L.; Gallo, R. C. Characterization of liposome-mediated gene delivery: expression, stability and pharmacokinetics of plasmid DNA. Gene Therapy 1997, 4, 226-237.

24. Chowdhury, N. R.; Wu, C. H.; Wu, G. Y.; Yerneni, P. C.; Bommineni, V. R.; Chowdhury, J . R. Fate of DNA targeted to the liver by asialoglycoprotein receptor-mediated endocytosis in vivo. Prolonged persistence in cytoplasmic vesicles after partial hepatectomy. J . Biol. Chem. 1993, 268, 1126571.

25. McKenzie, D. L.; Collard, W. T.; Rice, K. G. Comparative gene transfer efficiency of low molecular weight polylysine DNA condensing peptides. I. Pept. Res. 1999, in press

26. Wagner, E.; Cotten, M.; Foisner, R.; Birnstiel, M. L. Transferrin-polycation-DNA complexes: the effect of polycations on the structure of the complex and DNA delivery to cells. Proc. Natl. Acad. Sci. U.S.A. 1991, 88, 4255-9.

27. Haensler, J .; Szoka, F. C., J r. Synthesis and characterization of a trigalactosylated bisacridine compound to target DNA to hepatocytes. Bioconjugate Chem. 1993, 4, 85-93.

28. Batra, R. K., F. Wang-J ohanning, E. Wagner, R. I. Garver, J r., and D. T. Curiel. Receptor-mediated gene delivery employing lectin-binding specificity. Gene Ther. 1994, 1, 255-60.

29. Plank, C.; Mechtler, K.; Szoka, F. C., J r.; Wagner, E. Activation of the complement system by synthetic DNA complexes: a potential barrier for intravenous gene delivery. Human Gene Ther. 1996, 7, 1437-46.

30. Gratzer, P. F.; Pereira, C. A.; Lee, M. J . Solvent environment modulates effects of glutaraldehyde cross-linking on tissuederived biomaterials. J . Biomed. Mater. Res. 1996, 31, 533543

31. Ege, S. Organic Chemi stry: Structure and Reactivity; Heath, D. C., Co.: Lexington, KY, 1994.

\section{Acknowledgments}

The authors acknowledge technical support provided by Ron Kelly and financial support provided by NIH grants GM 48049, DE 13004, NIH predoctoral fellowship (R.C.A.) and support from Selective Genetics Inc.

J S990042P 